\title{
Development and Validation of a HPLC-UV Method for Extraction Optimization and Biological Evaluation of Hot-Water and Ethanolic Extracts of Dendropanax morbifera Leaves
}

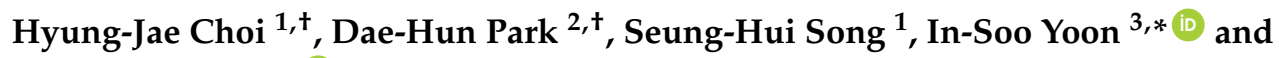 \\ Seung-Sik Cho ${ }^{1, *(D)}$ \\ 1 Department of Pharmacy, College of Pharmacy and Natural Medicine Research Institute, Mokpo National \\ University, Muan, Jeonnam 58554, Korea; qweert15@naver.com (H.-J.C.); tmdgm17898@naver.com (S.-H.S.) \\ 2 Department of Nursing, Dongshin University, Naju, Jeonnam 58245, Korea; dhj1221@hanmail.net \\ 3 Department of Manufacturing Pharmacy, College of Pharmacy, Pusan National University, Geumjeong, \\ Busan 46241, Korea \\ * Correspondence: insoo.yoon@pusan.ac.kr (I.-S.Y.); sscho@mokpo.ac.kr (S.-S.C.); \\ Tel.: +82-51-510-2806 (I.-S.Y.); +82-61-450-2687 (S.-S.C.) \\ + These authors contributed equally to this work.
}

Received: 22 February 2018; Accepted: 12 March 2018; Published: 13 March 2018

\begin{abstract}
Dendropanax morbifera Leveille (Araliaceae) has been used in traditional oriental remedies for cancer, inflammation, diabetes, and thrombosis. However, a validated analytical method, standardization, and optimization of extraction conditions with respect to biological activity have not been reported. In this study, a simple and validated HPLC method for identifying and quantifying active substances in D. morbifera was developed. Hot water and ethanolic D. morbifera leaf extracts from different production regions were prepared and evaluated with regard to their chemical compositions and biological activities. The contents of active compounds such as rutin and chlorogenic acid were determined in four samples collected from different regions. The $80 \%$ ethanolic extract showed the best antioxidant activity, phenolic content, reducing power, and xanthine oxidase (XO) inhibitory activity. The validated HPLC method confirmed the presence of chlorogenic acid and rutin in D. morbifera leaf extracts. The antioxidant and XO inhibitory activity of $D$. morbifera extract could be attributed to the marker compounds. Collectively, these results suggest that $D$. morbifera leaves could be beneficial for the treatment or prevention of hyperuricemia-related disease, and the validated HPLC method could be a useful tool for the quality control of food or drug formulations containing D. morbifera.
\end{abstract}

Keywords: Dendropanax morbifera; extraction optimization; HPLC; xanthine oxidase

\section{Introduction}

Dendropanax morbifera Leveille is a subtropical evergreen tree which belongs to the family Araliacea, and it has been used in traditional medicines for the treatment of infectious diseases, dermatopathy, and headaches [1]. Previous studies have reported that D. morbifera exhibit various pharmacological effects, including antioxidant [2], antidiabetic [3], hepatoprotective [4], anticomplementary [5], and antiatherogenic activities [6]. D. morbifera leaf has also been traditionally used as a botanical remedy in Asia [7]. The efficacy of extracts and active constituents prepared with $D$. morbifera leaves as a medicinal source has been investigated in a few studies to date. Several research studies have reported various pharmacological activities of D. morbifera leaves and their 
active ingredients identified, which are listed in Table 1. Recently there has been a great effort to find candidates from natural products to effectively control metabolic disease [8].

D. morbifera leaves were reported to possess antioxidant and anticancer activities by moduating cellular apoptosis in various human tumor cell lines such as colon adenocarcinoma cells, biliary tract cells, hepatocellular carcinoma cells, and human osteocarcinoma cells [1]. Additionally, anti-inflammatory, antithrombotic, and other activities were found in D. morbifera leaf extracts, as shown in Table 1 . However, the effects of $D$. morbifera leaf extracts on the activity of xanthine oxidase (XO) have not been reported. In the previous reports listed in Table 1, D. morbifera leaf extracts were prepared with organic solvents such as ethanol, methanol, and chloroform. However, there have been few studies on the optimization of extraction conditions with respect to biological activity, phytochemical contents, or both.

Table 1. Pharmacological activities and/or chemical constituents of D. morbifera leaf extracts reported in previous literatures.

\begin{tabular}{ccccc}
\hline Ext. Solvent & Activity & Chemical Identified & Region & Ref. \\
\hline chloroform & anti-inflammatory & - & - & {$[4]$} \\
\hline $70 \%$ ethanol & anticancer & - & - & {$[9]$} \\
\hline- & anti-inflammatory & oleifoliside A & - & {$[10]$} \\
\hline chloroform & kidney damage & - & - & {$[11]$} \\
\hline- & anticomplement & three polyacetylenes & - & {$[5]$} \\
\hline methanol & anti-inflammatory & rutin and 21 compounds & Jeju, Korea & {$[12]$} \\
\hline \multirow{2}{*}{$80 \%$ ethanol } & $\begin{array}{c}\text { antioxidant } \\
\text { anticancer }\end{array}$ & caffeic acid, rutin, rosmarinic acid & Jeju, Korea & {$[1]$} \\
\hline- & Antithrombotic & rutin & Wando, Korea & {$[13]$} \\
\hline- & Anticancer & oleifoliside B & - & {$[14]$} \\
\hline- & Neurogenerative & rutin & Wando, Korea & {$[15]$} \\
\hline
\end{tabular}

Recently, considerable effort has been focused on developing D. morbifera leaf as a therapeutic or functional source, but no positive results have been reported. To facilitate the pharmaceutical industrialization of D. morbifera leaf, a standardization process of the plant material with marker compounds identified using validated analytical methods is highly required. However, no validated analytical methods for the standardization and optimization of the biological properties of D. morbifera preparations have been reported in the literature. Here, we report the preparation of various hot water and ethanolic extracts of D. morbifera leaves collected from four different regions in Korea as well as the development of a simple and validated high-performance liquid chromatography (HPLC) method for chemical profiling and standardization of the plant extracts. In addition, the extraction process was optimized for phenolic contents and biological activities such as antioxidant and XO inhibitory activity.

\section{Results and Discussion}

\subsection{Optimization of Chromatographic Conditions}

The HPLC conditions were optimized for the mobile phase composition, column temperature, wavelength, and flow rate (data not shown). A gradient program was used to separate the active markers in a single run within a reasonable period. Detection wavelengths were set according to the ultraviolet (UV) absorption maxima of the compounds $(330 \mathrm{~nm})$. The chemical structures of the active constituents identified and representative chromatograms of the standard mixture and sample extracts are shown in Figure 1. 


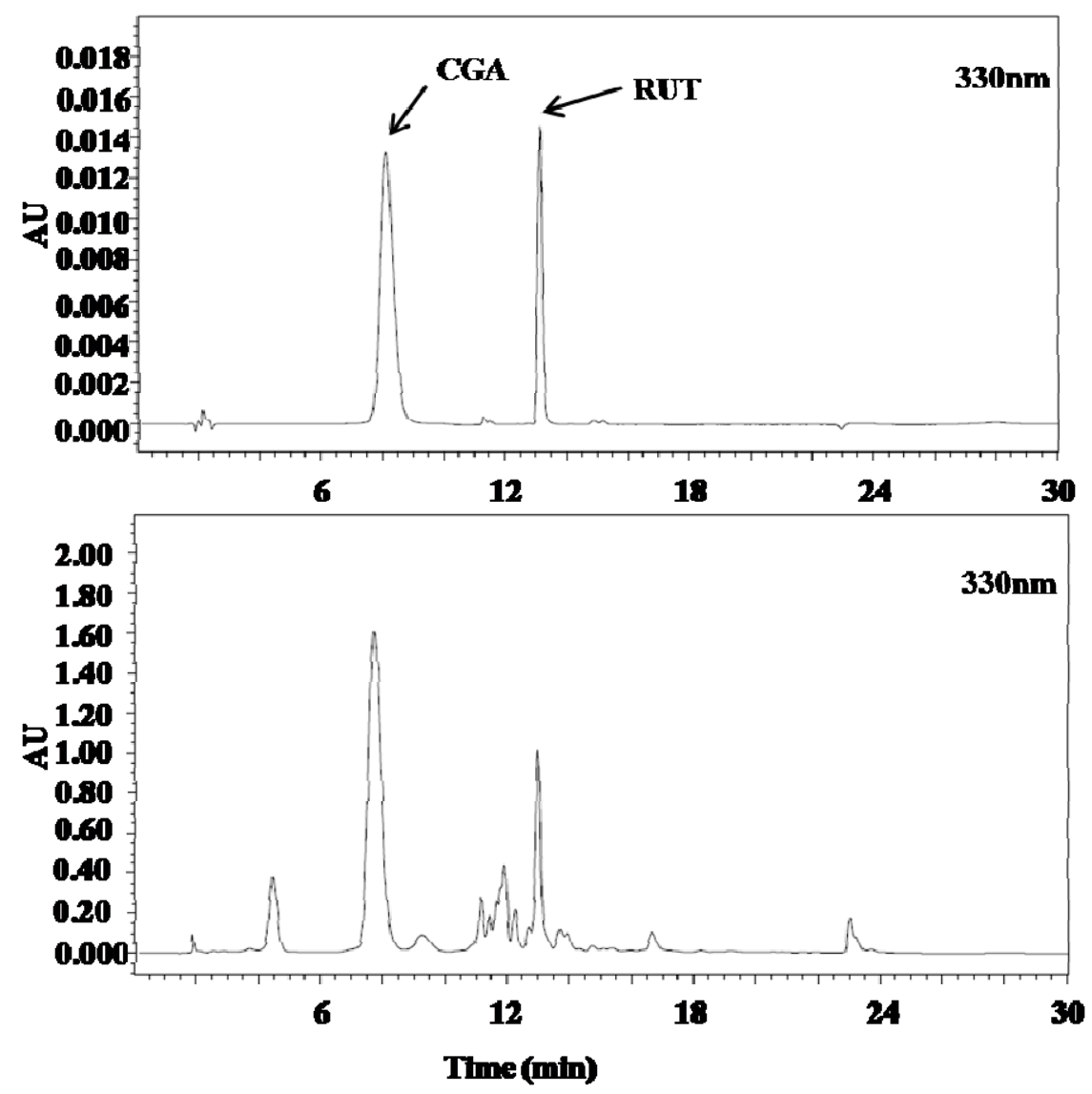

Figure 1. Chromatogram of standard and D. morbifera leaf extract.

\subsection{Method Validation}

The limit of detection (LOD) of an analytical procedure is the lowest amount of an analyte in a sample that can be detected but not necessarily quantified [16] while the limit of quantification (LOQ) is the lowest level in the linear concentration range with acceptable precision and accuracy. The LOD of the present method was 0.65 and $0.50 \mu \mathrm{g} / \mathrm{mL}$ for chlorogenic acid and rutin, respectively (Table 2), and the corresponding LOQ values were 2.13 and $1.64 \mu \mathrm{g} / \mathrm{mL}$, respectively (Table 2). Calibration curves were linear over a concentration range of $6.25-50 \mu \mathrm{g} / \mathrm{mL}$ for the two markers. The calibration curves exhibited good linear regressions (coefficient of determination $r^{2}>0.999$ for chlorogenic acid and rutin, Table 2).

Table 2. HPLC data of calibration graphs and limit of quantification and detection of two markers.

\begin{tabular}{cccccc}
\hline Analyte & Retention Time $(\mathrm{min})$ & $r^{2}$ & Range $(\mu \mathrm{g} / \mathrm{mL})$ & LOQ $(\mu \mathrm{g} / \mathrm{mL})$ & LOD $(\mu \mathrm{g} / \mathrm{mL})$ \\
\hline Chlorogenic acid & 7.7 & 0.9988 & $3.125-50$ & 2.13 & 0.65 \\
Rutin & 12.7 & 0.9996 & $3.125-50$ & 1.64 & 0.50 \\
\hline
\end{tabular}

The results of the intraday and interday precision experiments are shown in Table 3. The developed method was precise, as indicated by the relative standard deviation (RSD) values (less than $2.5 \%$ ) for the repeatability of the intraday and interday precision studies, which were below the limit recommended by the International Conference on Harmonisation (ICH) guidelines [17]. The overall recovery percentages were in the range of $92.36-98.12 \%$ for chlorogenic acid and 98.36-106.83\% for rutin. These results demonstrate that the developed method was reproducible with good accuracy (Table 3). 
Table 3. Analytical results of intra-day and inter-day precision and accuracy.

\begin{tabular}{cccccc}
\hline \multirow{2}{*}{ Analyte } & \multirow{2}{*}{ Conc. $(\boldsymbol{\mu g} / \mathbf{m L})$} & \multicolumn{2}{c}{ Intra-Day $(\boldsymbol{n}=\mathbf{3})$} & \multicolumn{2}{c}{ Inter-Day $(\boldsymbol{n}=\mathbf{3})$} \\
\cline { 3 - 6 } & & RSD (\%) & Accuracy (\%) & RSD (\%) & Accuracy (\%) \\
\hline \multirow{3}{*}{ Chlorogenic acid } & 12.5 & 4.73 & 92.36 & 1.17 & 94.78 \\
& 25 & 1.11 & 95.70 & 1.64 & 97.07 \\
& 50 & 2.12 & 96.12 & 1.95 & 98.12 \\
\hline \multirow{3}{*}{ Rutin } & 12.5 & 3.18 & 100.65 & 7.15 & 106.83 \\
& 25 & 1.00 & 99.07 & 5.71 & 102.17 \\
& 50 & 1.19 & 98.36 & 1.83 & 100.60 \\
\hline
\end{tabular}

The results of the repeatability experiments are shown in Table 4. The developed method was precise; the RSD values for the repeatability precision studies were below $2.0 \%$.

Table 4. Analytical recovery data $(n=6)$.

\begin{tabular}{cccc}
\hline Analyte & Added $(\boldsymbol{\mu g} / \mathbf{m L})$ & Recovery $(\%)($ Mean $\pm \mathbf{S D})$ & RSD $(\%)$ \\
\hline \multirow{3}{*}{ Chlorogenic acid } & 12.5 & $95.77 \pm 0.62$ & 0.78 \\
& 25 & $96.72 \pm 1.33$ & 1.50 \\
& 50 & $98.21 \pm 0.45$ & 0.48 \\
\hline \multirow{2}{*}{ Rutin } & 12.5 & $102.73 \pm 0.40$ & 0.40 \\
& 25 & $97.65 \pm 1.49$ & 1.56 \\
& 50 & $98.64 \pm 0.43$ & 0.43 \\
\hline
\end{tabular}

\subsection{Contents of Marker Compounds in D. morbifera from Different Cultivation Regions}

Plant samples were collected from four different cultivation regions to compare the extraction yield and productivity of the active substances. The extraction yield and content of markers were compared for the various hot water extracts of the plant. The validated HPLC method was used to analyze the four different extracts. Chlorogenic acid and rutin were commonly identified in all samples. The extraction yield of samples from the various regions decreased in the following order: Jangheung $(\mathrm{JH}, 13.46 \%)>$ Wando $(\mathrm{W}, 12.03 \%)>$ Kangjin $(\mathrm{K}, 11.0 \%)>\mathrm{Jeju}(\mathrm{JJ}, 8.2 \%)$, indicating that the JJ sample showed the lowest yield. The average amounts (wt \%) of chlorogenic acid and rutin are presented in Figure 2.
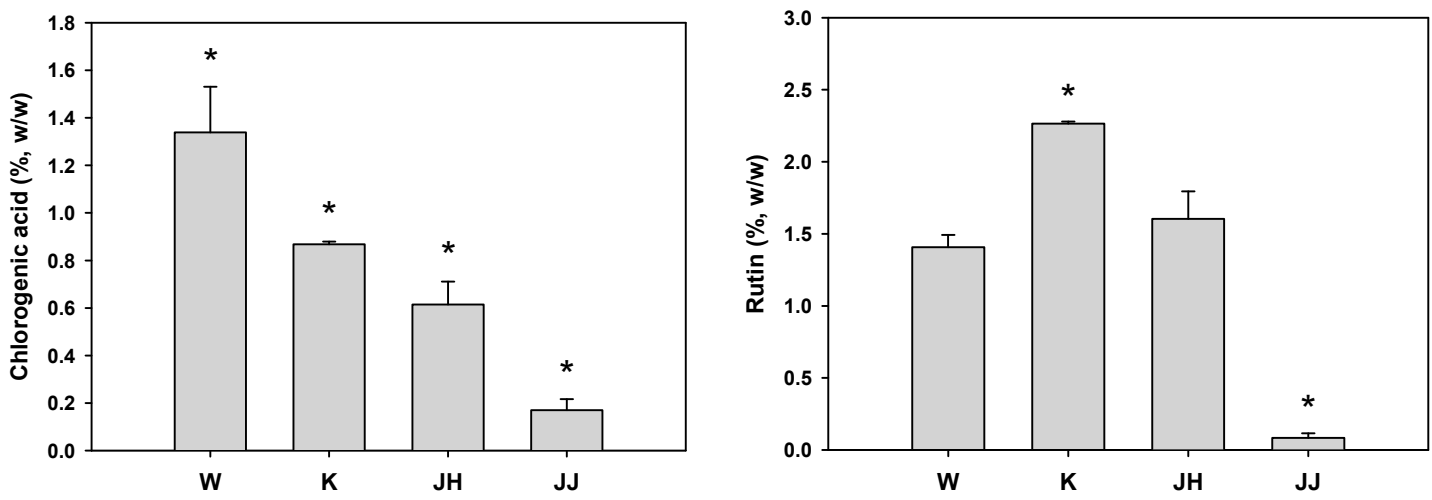

Figure 2. Contents of chlorogenic acid and rutin in hot water extracts of $D$. morbifera leaf from different cultivation regions. W: Wando, K: Kangjin, JH: Jangheung, JJ: Jeju. The asterisk represents a value significantly different from the other groups $(p<0.05)$. Values are mean \pm standard deviation $(n=3)$.

The contents of chlorogenic acid were highest in the W sample, while the contents of rutin were highest in the K sample. The sum of the two active ingredient contents (chlorogenic acid and rutin) of $\mathrm{W}$ and $\mathrm{K}$ was comparable to each other, whereas the extraction yield of $\mathrm{W}$ was higher than that of $\mathrm{K}$. Thus, D. morbifera from region $\mathrm{W}$ was used for further experiments. 


\subsection{Contents of Marker Compounds in D. morbifera Leaf Extracts}

Six extracts, hot water and ethanolic extract with varying ethanol contents (20 to $100 \%, v / v$ ) were prepared and compared with respect to the marker contets using the validated HPLC method. The average contents (wt \%) of both markers are presented in Figure 3, and their levels in the $80 \%$ ethanolic extract were greater than those in the other ethanolic extracts (chlorogenic acid: $4.71 \pm 0.06 \%$; rutin: $3.29 \pm 0.04 \%$ ). Thus, $80 \%$ ethanol was selected as the most efficient extraction solvent.
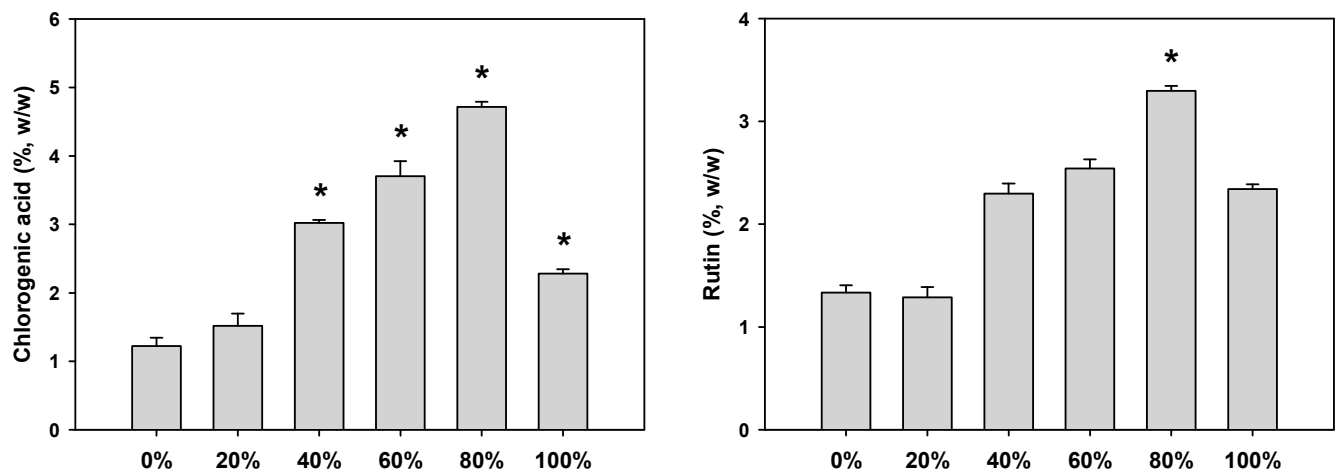

Figure 3. Contents of chlorogenic acid and rutin in hot water ( $0 \%)$ and ethanolic extracts (20-100\%) of D. morbifera leaf. Ethanolic extracts were prepared with $20-100 \%$ ethanol. The asterisk represents a value significantly different from the other groups $(p<0.05)$. Values were the mean \pm standard deviation $(n=3)$.

\subsection{Antioxidant Activity and Total Phenolic Contents of D. morbifera Extracts}

The antioxidant potential of various ethanoilc extracts of D. morbifera was determined using the 2,2-diphenyl-1-picrylhydrazyl (DPPH) scavenging and reducing power assays. The DPPH scavenging assay is a fast and easy method for evaluating the free radical scavenging ability of given samples. The antioxidant effects of plant extracts are generally related to the phenolic contents, and phenolic-rich sources of phytochemicals with antioxidant activity have curative benefits against conditions such as inflammation, oxidative stress, and other metabolic diseases [17].

The antioxidative properties of the test plant extracts were closely correlated with the composition of active compounds such as phenolics. Therefore, we compared the phenolic contents (mg/g as gallic acid) of the various D. morbifera leaf extracts. The DPPH radical scavenging activity is shown in Figure 4. The $80 \%$ ethanolic extract showed the highest DPPH radical scavenging activity $(36.10 \pm 2.68 \%)$ with a half-maximal inhibitory concentration $\left(\mathrm{IC}_{50}\right)$ of $116.97 \mu \mathrm{g} / \mathrm{mL}$.

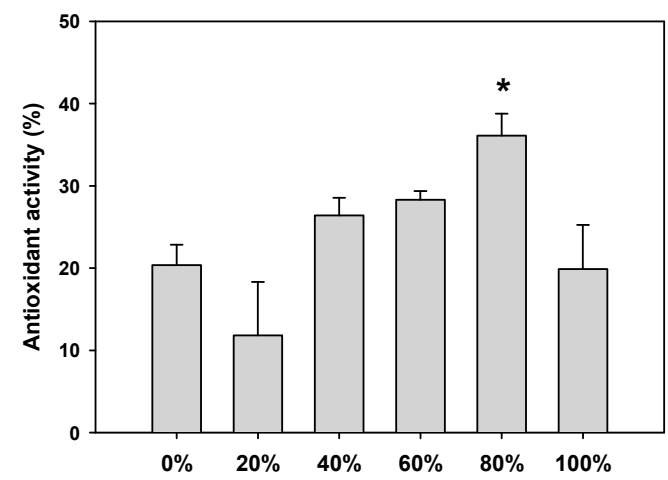

Figure 4. DPPH scavenging activity of ethanolic extracts of D. morbifera leaf. Ethanolic extracts were prepared with $20-100 \%$ ethanol. The asterisk represents a value significantly different from the other groups $(p<0.05)$. Values were the mean \pm standard deviation $(n=3)$. 
The reducing power assay is also very useful for evaluating the antioxidant activity. In the present study, we tested the reductive capability of extract sample by measuring the reduction of $\mathrm{Fe}^{3+}$. The $80 \%$ ethanolic extract exhibited the highest activity among the six extracts (Table 5). The reductive activity expressed as vitamin $C$ equivalents was $17.70 \pm 0.40 \mu \mathrm{g} / 100 \mu \mathrm{g}$. The total phenolic content was determined using the Folin-Ciocalteu method [17], and it was reported as gallic acid equivalents by referencing the standard curve $\left(r^{2}>0.999\right)$, as shown in Table 5 . The phenolic content of the $80 \%$ ethanolic extract was higher than that of the other ethanolic extracts $(57.89 \pm 2.6 \mathrm{mg} / \mathrm{g}$ as gallic acid equivalents). Taken together, the results indicate that the DPPH radical scavenging activity, reducing power, and phenolic content were significantly higher in the $80 \%$ ethanolic extract than in the other extracts.

Table 5. Reducing power and total phenolic contents of D. morbifera leaf extracts.

\begin{tabular}{ccc}
\hline Extract & $\begin{array}{c}\text { Reducing Power } \\
\text { (Ascorbic Acid eq. } \boldsymbol{\mu g} / \mathbf{1 0 0} \boldsymbol{\mu g} \text { Extract) }\end{array}$ & $\begin{array}{c}\text { Total Phenolic Content } \\
\text { (Gallic Acid eq. } \mathbf{~ m g / g )}\end{array}$ \\
\hline Water & $8.4 \pm 0.2$ & $30.27 \pm 0.6$ \\
20\% EtOH Ex & $7.4 \pm 0.7$ & $26.3 \pm 0.6$ \\
$40 \%$ EtOH Ex & $12.3 \pm 0.5$ & $39.28 \pm 1.4$ \\
$60 \%$ EtOH Ex & $13.6 \pm 0.2$ & $52.30 \pm 2.9$ \\
$80 \%$ EtOH Ex & $17.7 \pm 0.4$ & $57.89 \pm 2.6$ \\
$100 \%$ EtOH Ex & $5.5 \pm 1.3$ & $34.72 \pm 1.3$ \\
\hline
\end{tabular}

\subsection{XO Inhibitory Activity of D. morbifera Extracts}

The effect of ethanol concentration on the XO inhibitory activity of $D$. morbifera leaf ethanolic extracts is shown in Figure 5. Allopurinol (ALP, positive control) at a concentration of $50 \mu \mathrm{g} / \mathrm{mL}$ significantly inhibited XO activity $(82.08 \pm 0.82 \%)$. The $\mathrm{XO}$ inhibitory activity of the ethanolic extracts was significantly higher in the $80 \%$ ethanolic extract than the other extracts. The XO inhibitory activity of the $80 \%$ ethanolic extract tended to increase in a concentration-dependent manner with increasing the extract concentration tested by up to $2 \mathrm{mg} / \mathrm{mL}$ (data not shown). Previously, we reported four different botanical extracts as potential XO inhibitors [18]. Yoon et al. [19,20] reported that the optimized extracts of Corylopsis coreana and Camellia japonica inhibited XO activity by approximately $50 \%$ at a concentration of $2 \mathrm{mg} / \mathrm{mL}$. Additionally, Yoon et al. [18] demonstrated that Quercus acuta extract showed approximately 50\% XO inhibitory activity at a concentration of $1 \mathrm{mg} / \mathrm{mL}$. Cudrania tricuspidata extract inhibited $\mathrm{XO}$ by approximately $75 \%$ at a concentration of $2 \mathrm{mg} / \mathrm{mL}$ [21]. The plant extracts with $\mathrm{XO}$ inhibitory activity at 1 and $2 \mathrm{mg} / \mathrm{mL}$ demonstrated consistent effects in the in vivo animal disease model. Thus, it is plausible that the $80 \%$ ethanolic extract of $D$. morbifera leaves could be developed as a candidate antihyperuricemic agent.

We identified chlorogenic acid and rutin as marker compounds of extracts of $D$. morbifera leaves from different cultivation regions. In the present study, we confirmed that these two compounds were common constituents of the D. morbifera leaves from all four regions. This finding could be important in the use of this plant for industrial purpose. Furthermore, we established the optimal analysis methods and optimized the extraction conditions for further studies. Rutin is a flavonoid known to have diverse pharmacological effects such as antihyperuricemia, anti-inflammatory, anticonvulsant, and anti-Alzheimer's disease [19,22-24]. A previous study reported that rutin at doses of 50 and $100 \mathrm{mg} / \mathrm{kg}$ markedly reduced biological markers in hyperuricemic mice [23]. In another study, rutin exhibited antihyperuricemic effects by inhibiting xanthine dehydrogenase/ XO activity [24]. Chlorogenic acid has also been reported to have diverse pharmacological effects such as anti-inflammatory, antiallergic, and antihyperuricemic effects [25-28]. Meng et al. [27] reported that chlorogenic acid has anti-gout activity by inhibiting $\mathrm{XO}$ activity. Chlorogenic acid also decreased the levels of proinflammatory cytokines such as interleukin (IL)-1 $\beta$, IL-6, and tumor necrosis factor (TNF)- $\alpha$ induced by uric acid [27-29]. These results suggest that chlorogenic acid may have considerable potential for development as an antihyperuricemic agent. 
As shown in Table 1, previous studies reported the diverse activities of extracts of D. morbifera leaves. However, to the best of our knowledge, our present study is the first to report the optimization of the extraction process of pharmaceutically active indicators from $D$. morbifera leaves from various regions and the comparation of antioxidant and XO inhibitory activities of various regionspecific extracts.

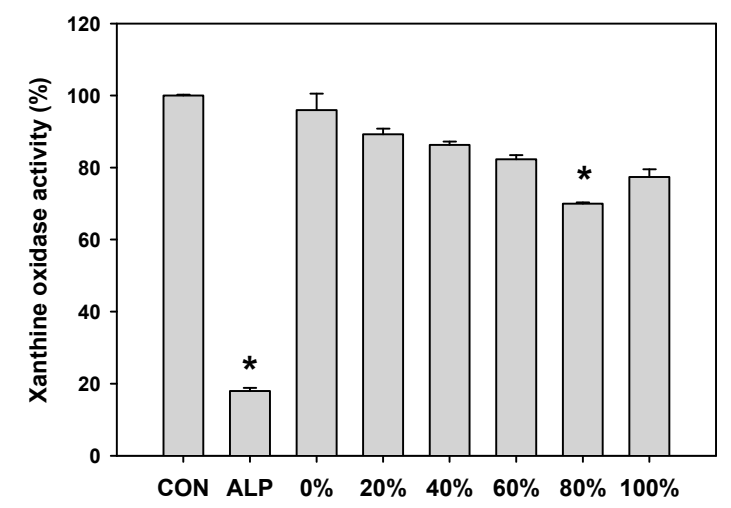

Figure 5. Xanthine oxidase inhibitory activities in ethanolic (0-100\%) extracts of D. morbifera leaves $(2 \mathrm{mg} / \mathrm{mL}$ ) and allopurinol (ALP, $50 \mu \mathrm{g} / \mathrm{mL})$. Ethanolic extracts were prepared with $20-100 \%$ ethanol. The asterisk represents a value significantly different from the other groups $(p<0.05)$. Values were the mean \pm standard deviation $(n=3)$.

A standard analytical method is crucial for the industrial application of plant extracts, and extraction optimization is an essential process for the optimization and quality control of natural products from various sources. However, there has been no report of a standard profile for D. morbifera. Moreover, currently, no other validated HPLC method has been reported for the simultaneous determination of chlorogenic acid and rutin in the Dendropanax genus. In Korea, one species of D. morbifera is mainly cultivated in four different regions studied ( $\mathrm{W}, \mathrm{K}, \mathrm{JH}$, and JJ). In this study, the differences in the marker content of samples from the four production regions were compared using our validated HPLC methods, which showed efficiency in the analysis and optimization of the D. morbifera leaf preparations. Moreover, the findings of the present study could be applied to the industrialization of $D$. morbifera by providing basic information on samples from the four cultivation regions in Korea.

\section{Experimental Section}

\subsection{Plant Material and Extract Preparation}

D. morbifera leaves were collected in October 2016 near Wando (34.3110596 N, 126.755054 E), Kangjin (34.642077 N, 126.76726 E), and Jangheung (34.681685 N, 126.906927 E) in Jeonnam Province, Korea and Jeju (33.499621 N, 126.531188 E) in Jeju Province, Korea. Voucher specimens (MNUCSS-DMWD-01, MNUCSS-DMJH-01, MNUCSS-DMHN-01, and MNUCSS-DMJJ-01) were deposited at the College of Pharmacy, Mokpo National University (Muan, Korea). For the present study, the air-dried, powdered D. morbifera leaves (50 g) were extracted twice with 20-100\% ethanol $(300 \mathrm{~mL})$ at room temperature for 3 days. The $0 \%$ extract was prepared as hot-water extract $\left(100^{\circ} \mathrm{C}\right.$, $4 \mathrm{~h}$ ). After filtration, the resultant ethanol solution was evaporated, freeze-dried, and stored at $-50^{\circ} \mathrm{C}$. The crude extract was resuspended in ethanol and filtered using a 0.4- $\mu \mathrm{m}$ membrane. All the samples were subjected to extraction optimization and used in the in vitro experiments.

\subsection{Chromatographic Conditions}

All analyses were performed using an Alliance 2695 HPLC system (Waters, Milford, MA, USA) equipped with a photodiode array detector. A revese phase C18 analytical column (5- $\mu \mathrm{m}$, 
$150 \mathrm{~mm} \times 5 \mathrm{~mm}$ ) was used with a mobile phase consisting of a mixture of solvent A (acetonitrile) and $\mathrm{B}(0.2 \%$ phosphoric acid). A gradient elution (from $10 / 90$ to $80 / 20 \mathrm{v} / \mathrm{v}$ ) at a flow rate of $0.8 \mathrm{~mL} / \mathrm{min}$ was used and the analytical conditions are described in Table 6.

Table 6. Analytical conditions of HPLC system for analyzing two markers.

\begin{tabular}{|c|c|c|c|}
\hline Parameters & \multicolumn{3}{|c|}{ Conditions } \\
\hline Column & \multicolumn{3}{|c|}{$\begin{array}{c}\text { Zorbax extended-C18 } \\
(\mathrm{C} 18,4.6 \mathrm{~mm} \times 150 \mathrm{~mm}, 5 \mu \mathrm{m})\end{array}$} \\
\hline Flow rate & \multicolumn{3}{|c|}{$0.8 \mathrm{~mL} / \mathrm{min}$} \\
\hline Injection volumn & \multicolumn{3}{|c|}{$10 \mu \mathrm{L}$} \\
\hline UV detection & \multicolumn{3}{|c|}{$330 \mathrm{~nm}$} \\
\hline Run time & \multicolumn{3}{|c|}{$30 \mathrm{~min}$} \\
\hline \multirow{8}{*}{ Gradient } & Time (min) & $\% \mathrm{~A}$ & $\% \mathrm{~B}$ \\
\hline & 0 & 10 & 90 \\
\hline & 7 & 10 & 90 \\
\hline & 8 & 20 & 80 \\
\hline & 20 & 25 & 75 \\
\hline & 21 & 100 & 0 \\
\hline & 25 & 10 & 90 \\
\hline & 30 & 10 & 90 \\
\hline
\end{tabular}

\subsection{Method Validation}

The analytical method used for the quantification of chlorogenic acid and rutin in the D. morbifera leaf extracts was validated for specificity, linearity, sensitivity, accuracy, precision, and recovery, as previously described [17].

\subsection{Analysis of D. morbifera Leaf Extracts}

The HPLC method developed inthis study was used to quantitatively determine the chlorogenic acid and rutin contents in the extracts of $D$. morbifera leaves.

\subsection{DPPH Free Radical Assay}

The DPPH radical scavenging assay was used to evaluate the antioxidant properties of the extracts. Briefly, various concentrations of the ethanolic extract solutions $(0.5 \mathrm{~mL})$ were mixed with $0.4 \mathrm{mM}$ DPPH $(0.5 \mathrm{~mL})$ for $10 \mathrm{~min}$. The absorbance at $517 \mathrm{~nm}$ was measured using a microplate reader (Perkin Elmer, Waltham, MA, USA). The radical scavenging activity was calculated as a percentage using the following equation:

$$
\text { DPPH radical scavenging activity }(\%)=\left[1-\left(\mathrm{A}_{\text {sample }} / \mathrm{A}_{\text {blank }}\right)\right] \times 100
$$

$\mathrm{IC}_{50}(\mu \mathrm{g} / \mathrm{mL})$ values were calculated from the data of the DPPH free radical scavenging activities of the various samples [17].

\subsection{Reducing Power}

The reducing power assay was also used to evaluate the antioxidant properties of the extracts. The extract $(0.1 \mathrm{~mL})$ was mixed with $0.2 \mathrm{M}$ sodium phosphate buffer $(0.5 \mathrm{~mL})$, and $1 \%$ potassium ferricyanide $(0.5 \mathrm{~mL})$, followed by incubation at $50{ }^{\circ} \mathrm{C}$ for $20 \mathrm{~min}$ and the reaction was stopped by adding $10 \%$ trichloroacetic acid solution $(0.5 \mathrm{~mL})$. The mixture was centrifuged at $2000 \times g$ for $10 \mathrm{~min}$, the supernatant was mixed with distilled water $(0.5 \mathrm{~mL})$ and $0.1 \%$ iron (III) chloride solution $(0.1 \mathrm{~mL})$, and the absorbance of the final mixture was measured at $700 \mathrm{~nm}$. The reducing powers of the various samples were expressed as vitamin C equivalents [17]. 


\subsection{Total Phenolic Content}

The total phenolic content was determined using the Folin-Ciocalteu assay. An extract solution $(1 \mathrm{~mL})$ or standard (gallic acid) was mixed with $1 \mathrm{~mL}$ each of $2 \%$ sodium carbonate and $10 \%$ Folin-Ciocalteu phenol reagent for $10 \mathrm{~min}$. The absorbance of the mixture was then measured at $750 \mathrm{~nm}$ using a microplate reader (Perkin Elmer, Waltham, MA, USA). The measurement was compared to a calibration curve constructed using gallic acid standard concentrations. The results were expressed as milligrams of gallic acid equivalents per gram of the sample [17].

\subsection{XO Inhibitory Activity In Vitro}

The XO inhibitory activity was measured according to a previous report [19]. Briefly, $0.1 \mathrm{~mL}$ of each sample was mixed with $0.6 \mathrm{~mL}$ phosphate buffer $(100 \mathrm{mM}, \mathrm{pH} 7.4), 0.1 \mathrm{~mL}$ XO $(0.2 \mathrm{U} / \mathrm{mL})$, and $0.2 \mathrm{~mL}$ xanthine $(1 \mathrm{mM}$, dissolved in $0.1 \mathrm{M}$ sodium hydroxide $[\mathrm{NaOH}])$ for $15 \mathrm{~min}$. The reaction was stopped by adding $0.2 \mathrm{~mL} 1 \mathrm{M}$ hydrochloric acid $(\mathrm{HCl})$, and the absorbance was measured at $290 \mathrm{~nm}$ with ALP as the positive control.

\subsection{Statistical Analysis}

All data were expressed as mean \pm standard deviation, and analysis of variance (post-hoc Tukey's multiple range test) was performed using the Statistical Package for the Social Sciences software (version 12.0, IBM Co., Armonk, NY, USA). A p-value less than 0.05 was considered to be statistically significant.

\section{Conclusions}

In the present study, hot water and ethanolic extracts of D. morbifera leaf extracts from four different cultivation regions were successfully prepared, and their chemical profiles and biological activities were evaluated. Hot water extracts from JH showed the highest yield and extract of the $\mathrm{W}$ and $\mathrm{K}$ samples showed high concentrations of the selected makers. The $80 \%$ ethanolic extract exhibited the most potent DPPH radical scavenging activity, reducing power, phenolic content, and XO inhibitory activity. The developed HPLC method was validated and applied to identify chlorogenic acid and rutin, which were found to be common constituents of all the D. morbifera leaf extracts. These findings suggest that the observed antioxidant and XO inhibitory activities of $D$. morbifera extracts were attributed, at least in part, to the marker compounds. To the best of our knowledge, this is the first study to report on a validated analytical method for the standardization and optimization of the biological properties of D. morbifera preparations. Further investigation is warranted to confirm the in vivo pharmacological activity of $D$. morbifera extract and its two constituents and assess the safe use of the plant. These propose efforts could lead to the development of D. morbifera as a potential, effective antioxidant and anti-hyperuricemic/gout agent.

Acknowledgments: This work was supported by the National Research Foundation of Korea (NRF) grant funded by the Korea government (MSIP; Ministry of Science, ICT \& Future Planning) (No. NRF-2017R1C1B5015187).

Author Contributions: In-Soo Yoon and Seung-Sik Cho conceived and designed the experiments. Hyung-Jae Choi, Seung-Hui Song and Seung-Sik Cho performed the experiments and analyzed the data. In-Soo Yoon and Dae-Hun Park statistically analyzed the data.

Conflicts of Interest: The authors declare no conflict of interest.

\section{References}

1. Hyun, T.K.; Kim, M.O.; Lee, H.; Kim, Y.; Kim, E.; Kim, J.S. Evaluation of anti-oxidant and anti-cancer properties of Dendropanax morbifera Leveille. Food Chem. 2013, 141, 1947-1955. [CrossRef] [PubMed]

2. Kim, W.; Kim, D.W.; Yoo, D.Y.; Jung, H.Y.; Kim, J.W.; Kim, D.W.; Choi, J.H.; Moon, S.M.; Yoon, Y.S.; Hwang, I.K. Antioxidant effects of Dendropanax morbifera Leveille extract in the hippocampus of mercury-exposed rats. BMC Complement. Altern. Med. 2015, 15, 247. [CrossRef] [PubMed] 
3. Moon, H.I. Antidiabetic effects of dendropanoxide from leaves of Dendropanax morbifera Leveille in normal and streptozotocin-induced diabetic rats. Hum. Exp. Toxicol. 2011, 30, 870-875. [CrossRef] [PubMed]

4. Akram, M.; Kim, K.A.; Kim, E.S.; Syed, A.S.; Kim, C.Y.; Lee, J.S.; Bae, O.N. Potent anti-inflammatory and analgesic actions of the chloroform extract of Dendropanax morbifera mediated by the Nrf2/HO-1 pathway. Biol. Pharm. Bull. 2016, 39, 728-736. [CrossRef] [PubMed]

5. Chung, I.M.; Song, H.K.; Kim, S.J.; Moon, H.I. Anticomplement activity of polyacetylenes from leaves of Dendropanax morbifera Leveille. Phytother. Res. 2011, 25, 784-786. [CrossRef] [PubMed]

6. Chung, I.M.; Kim, M.Y.; Park, W.H.; Moon, H.I. Antiatherogenic activity of Dendropanax morbifera essential oil in rats. Pharmazie 2009, 64, 547-549. [PubMed]

7. Kim, J.M.; Park, S.K.; Guo, T.J.; Kang, J.Y.; Ha, J.S.; Lee, D.S.; Lee, U.; Heo, H.J. Anti-amnesic effect of Dendropanax morbifera via JNK signaling pathway on cognitive dysfunction in high-fat diet-induced diabetic mice. Behav. Brain Res. 2016, 312, 39-54. [CrossRef] [PubMed]

8. Waltenberger, B.; Mocan, A.; Smejkal, K.; Heiss, E.H.; Atanasov, A.G. Natural Products to Counteract the Epidemic of Cardiovascular and Metabolic Disorders. Molecules 2016, 21, 807. [CrossRef] [PubMed]

9. Lee, J.W.; Park, C.; Han, M.H.; Hong, S.H.; Lee, T.K.; Lee, S.H.; Kim, G.Y.; Choi, Y.H. Induction of human leukemia U937 cell apoptosis by an ethanol extract of Dendropanax morbifera Lev. through the caspase-dependent pathway. Oncol. Rep. 2013, 30, 1231-1238. [CrossRef] [PubMed]

10. Yu, H.Y.; Kim, K.S.; Lee, Y.C.; Moon, H.I.; Lee, J.H. Oleifolioside A, a new active compound, attenuates LPS-stimulated iNOS and COX-2 expression through the downregulation of NF-kappaB and MAPK activities in RAW 264.7 macrophages. Evid.-Based Complement. Altern. Med. 2012, 2012, 637512. [CrossRef] [PubMed]

11. Kim, E.S.; Lee, J.S.; Akram, M.; Kim, K.A.; Shin, Y.J.; Yu, J.H.; Bae, O.N. Protective activity of Dendropanax morbifera against cisplatin-induced acute kidney injury. Kidney Blood Press. Res. 2015, 40, 1-12. [CrossRef] [PubMed]

12. Hyun, T.K.; Ko, Y.-J.; Kim, E.-H.; Chung, I.-M.; Kim, J.-S. Anti-inflammatory activity and phenolic composition of Dendropanax morbifera leaf extracts. Ind. Crops Prod. 2015, 74, 263-270. [CrossRef]

13. Choi, J.H.; Kim, D.W.; Park, S.E.; Lee, H.J.; Kim, K.M.; Kim, K.J.; Kim, M.K.; Kim, S.J.; Kim, S. Anti-thrombotic effect of rutin isolated from Dendropanax morbifera Leveille. J. Biosci. Bioeng. 2015, 120, 181-186. [CrossRef] [PubMed]

14. Jin, C.Y.; Yu, H.Y.; Park, C.; Han, M.H.; Hong, S.H.; Kim, K.S.; Lee, Y.C.; Chang, Y.C.; Cheong, J.; Moon, S.K.; et al. Oleifolioside B-mediated autophagy promotes apoptosis in A549 human non-small cell lung cancer cells. Int. J. Oncol. 2013, 43, 1943-1950. [CrossRef] [PubMed]

15. Park, S.E.; Sapkota, K.; Choi, J.H.; Kim, M.K.; Kim, Y.H.; Kim, K.M.; Kim, K.J.; Oh, H.N.; Kim, S.J.; Kim, S. Rutin from Dendropanax morbifera Leveille protects human dopaminergic cells against rotenone induced cell injury through inhibiting JNK and p38 MAPK signaling. Neurochem. Res. 2014, 39, 707-718. [CrossRef] [PubMed]

16. Nile, S.H.; Kim, D.H. HPLC analysis, antioxidant, anti-inflammatory and xanthine oxidase inhibitory activity of Cudrania tricuspidata. Nat. Prod. Commun. 2015, 10, 1839-1842. [PubMed]

17. Seo, J.H.; Kim, J.E.; Shim, J.H.; Yoon, G.; Bang, M.A.; Bae, C.S.; Lee, K.J.; Park, D.H.; Cho, S.S. HPLC analysis, optimization of extraction conditions and biological evaluation of Corylopsis coreana Uyeki Flos. Molecules 2016, 21, 94. [CrossRef] [PubMed]

18. Yoon, I.S.; Park, D.H.; Bae, M.S.; Oh, D.S.; Kwon, N.H.; Kim, J.E.; Choi, C.Y.; Cho, S.S. In vitro and in vivo studies on Quercus acuta Thunb. (Fagaceae) extract: Active constituents, serum uric acid suppression, and xanthine oxidase inhibitory activity. Evid.-Based Complement. Altern. Med. 2017, 2017, 4097195. [CrossRef] [PubMed]

19. Yoon, I.S.; Park, D.H.; Kim, J.E.; Yoo, J.C.; Bae, M.S.; Oh, D.S.; Shim, J.H.; Choi, C.Y.; An, K.W.; Kim, E.I.; et al. Identification of the biologically active constituents of Camellia japonica leaf and anti-hyperuricemic effect in vitro and in vivo. Int. J. Mol. Med. 2017, 39, 1613-1620. [CrossRef] [PubMed]

20. Yoon, I.S.; Park, D.H.; Ki, S.H.; Cho, S.S. Effects of extracts from Corylopsis coreana Uyeki (Hamamelidaceae) flos on xanthine oxidase activity and hyperuricemia. J. Pharm. Pharmacol. 2016, 68, 1597-1603. [CrossRef] [PubMed]

21. Song, S.H.; Ki, S.H.; Park, D.H.; Moon, H.S.; Lee, C.D.; Yoon, I.S.; Cho, S.S. Quantitative analysis, extraction optimization, and biological evaluation of Cudrania tricuspidata leaf and fruit extracts. Molecules 2017, 22, 1489. [CrossRef] [PubMed] 
22. Ganeshpurkar, A.; Saluja, A.K. The pharmacological potential of rutin. Saudi Pharm. J. 2017, 25, 149-164. [CrossRef] [PubMed]

23. Chen, Y.S.; Hu, Q.H.; Zhang, X.; Zhu, Q.; Kong, L.D. Beneficial effect of rutin on oxonate-induced hyperuricemia and renal dysfunction in mice. Pharmacology 2013, 92, 75-83. [CrossRef] [PubMed]

24. Zhu, J.X.; Wang, Y.; Kong, L.D.; Yang, C.; Zhang, X. Effects of Biota orientalis extract and its flavonoid constituents, quercetin and rutin on serum uric acid levels in oxonate-induced mice and xanthine dehydrogenase and xanthine oxidase activities in mouse liver. J. Ethnopharmacol. 2004, 93, 133-140. [CrossRef] [PubMed]

25. Shi, H.; Shi, A.; Dong, L.; Lu, X.; Wang, Y.; Zhao, J.; Dai, F.; Guo, X. Chlorogenic acid protects against liver fibrosis in vivo and in vitro through inhibition of oxidative stress. Clin. Nutr. 2016, 35, 1366-1373. [CrossRef] [PubMed]

26. Zatorski, H.; Salaga, M.; Zielinska, M.; Piechota-Polanczyk, A.; Owczarek, K.; Kordek, R.; Lewandowska, U.; Chen, C.; Fichna, J. Experimental colitis in mice is attenuated by topical administration of chlorogenic acid. Naunyn-Schmiedebergs Arch. Pharmacol. 2015, 388, 643-651. [CrossRef] [PubMed]

27. Meng, Z.Q.; Tang, Z.H.; Yan, Y.X.; Guo, C.R.; Cao, L.; Ding, G.; Huang, W.Z.; Wang, Z.Z.; Wang, K.D.; Xiao, W.; et al. Study on the anti-gout activity of chlorogenic acid: Improvement on hyperuricemia and gouty inflammation. Am. J. Chin. Med. 2014, 42, 1471-1483. [CrossRef] [PubMed]

28. Hwang, S.J.; Kim, Y.W.; Park, Y.; Lee, H.J.; Kim, K.W. Anti-inflammatory effects of chlorogenic acid in lipopolysaccharide-stimulated RAW 264.7 cells. Inflamm. Res. 2014, 63, 81-90. [CrossRef] [PubMed]

29. Kim, H.R.; Lee, D.M.; Lee, S.H.; Seong, A.R.; Gin, D.W.; Hwang, J.A.; Park, J.H. Chlorogenic acid suppresses pulmonary eosinophilia, IgE production, and Th2-type cytokine production in an ovalbumin-induced allergic asthma: Activation of STAT-6 and JNK is inhibited by chlorogenic acid. Int. Immunopharmacol. 2010, 10, 1242-1248. [CrossRef] [PubMed]

Sample Availability: Samples of the compounds are not available from the authors.

(C) 2018 by the authors. Licensee MDPI, Basel, Switzerland. This article is an open access article distributed under the terms and conditions of the Creative Commons Attribution (CC BY) license (http://creativecommons.org/licenses/by/4.0/). 